\title{
DESIGN AND IMPLEMENTATION OF A FUZZY BASED TSUNAMI WARNING SYSTEM
}

\author{
Twinkle Tayal ${ }^{1}$, Prema KV ${ }^{2}$ \\ ${ }^{1} M . T e c h 2^{\text {nd }}$ year, ${ }^{2} \mathrm{HOD}, \mathrm{CSE}, \mathrm{FET}$, Mody University of Science and Technology, Rajasthan, India
}

\begin{abstract}
A tsunami can be referred to series of water waves initiated by the dislocation of a large quantity of water, usually in ocean or a large lake. Tsunamis obliterate not only human population but all other species. There are many factors that have potential to cause a tsunami like Earthquakes, volcanic eruptions and other underwater explosions (including explosions of underwater nuclear devices), landslides, meteorite impacts and other disturbances above or below water. With the preface of modern science and computer technology, the field of Artificial Intelligence is screening a definite efficacy in all continuum of life. There are certain ways to predict such disasters and design different kinds of early warning systems. These can be predicted on the basis of climatic conditions and several other parameters. One such concept that is working as a boom in the fields of environmental science and policy is fuzzy logic. As fuzzy logic can be widely stated as working with the vague, imprecise data and the linguistic terms. So, this methodology can be successfully applied in the field of tsunami warning as the influence of different parameters that cause tsunami is different and can be said as vague. In this work, a fuzzy system has been developed to declare the occurrence of tsunami in terms of linguistic parameters rare_tsunami, advisory_tsunami and warning by taking the tsunami characteristics earthquake magnitude, volcanic eruption index, landslide and height of waves in deep ocean. Fuzzy rule base is generated and the results are compared with an IEEE research paper.
\end{abstract}

Keywords: tsunami, tsunami warning system, design of tsunami warning system, Fuzzy logic, tsunami early warning system

\section{INTRODUCTION}

Tsunami is a Japanese word with the English interpretation, "harbor wave". It is represented by two characters, the first character, "tsu," which means harbor, and the second one, "nami" which means "wave". A tsunami is a very longwavelength wave of water which is generated by abrupt or sudden displacement of the seafloor or intrusion in the standing water. Tsunami is sometimes called as "seismic sea waves" by the scientific community and "tidal waves" by the local public. Tsunami waves are different from the normal sea waves in a way that the wavelength of tsunami is very long. Originally they look like a briskly rising tide, and due to this reason they are termed as tidal waves [1]. Though the impact of tsunamis is limited to coastal areas, their devastating power can be enormous and they can affect the entire ocean basins. There are several many recorded tsunamis in the history that caused destruction and were very ruinous. In addition to the appalling human loss of life and damage to habitations and infrastructure, the environment can be ruined by the impact of the access of salt water into the agricultural lands. The vegetation can be also badly influenced by the physical force of the waves, and the depth of the resultant flooding as the waves diminished [2]. There are several researches going on to predict this natural hazard, so that, people can be warned before. The effect of the natural hazard can't be minimized, but, if people warned earlier, it is possible to save many lives.
Several methods and algorithms are being used to predict the tsunami. On such method that can be used is "fuzzy logic". The compelling reason for selection of fuzzy logic model in this study is the natural fuzziness in the nature of tsunami and the difference of influence of different causes of tsunami.

\section{FUZZY LOGIC SYSTEM}

In 1965, L.A. Zadeh laid the fundamentals of fuzzy set theory [3] as a method to deal with the imprecision of practical systems. Bellman and Zadeh write that "Much of the decision making in the real world takes place in an environment in which the goals, the constraints and the consequences of possible actions are not known precisely" [4]. This "imprecision" or "fuzziness" is the staple of fuzzy sets or fuzzy logic applications. Fuzzy sets were anticipated as a generalization of standard set theory. Partially as result of this fact, fuzzy logic remained the preview of highly specialized and mathematical journals for many years [5]. The concept and application of fuzzy logic is becoming a tool of the essence in dealing the issues of environmental science and policy. It's becoming a general practice to deal with the linguistic terms. Fuzzy logic intention is to model human thinking and reasoning and to relate the model to problems according to the needs. When human solves problems, he generally creates verbal rules such as "if $<$ event realized $>$ is this, the <result> is that". Fuzzy logic tries to acquire these 
verbal rules and the ability to make decisions of humans to machines/computers. It uses verbal variables and linguistic terms along with verbal rules. Verbal rules and terms used in human decision-making process are fuzzy inspite of precise. Acquiring human logic system to computers/machines will strengthen problem-solving ability of computers/machines. Verbal terms and variables are expressed mathematically as membership degrees and membership functions. Fuzzy decision-making mechanisms use symbolic verbal phrases rather than using numeric values. Transferring these symbolic verbal phrases to computers is based on mathematics. This mathematical basis is nothing but fuzzy logic. Systems that use fuzzy logic are alternatives to the difficulty of mathematical modelling of complex non-linear problems and fuzzy logic meets mathematical modelling requirement of a system and can produce effective results based on indefinite verbal knowledge as humans. In fuzzy logic, information is verbal phrases or can say linguistic terms such as big, small, very, few etc. inspite of using numeric values. If a system's behaviour can be expressed by rules or requires very complex non-linear processes, fuzzy logic approach can be applied in that system [6].

\subsection{Mamdani's Fuzzy Inference Method}

Mamdani's fuzzy inference method is the most widely seen fuzzy methodology. It was among the first control systems built using fuzzy set theory. It was proposed in 1975 by Ebrahim Mamdani as an effort to control a steam engine and boiler combination by synthesizing a set of linguistic control rules achieved from skilled human operators. Mamdani's attempt was based on Lotfi Zadeh's 1973 paper on fuzzy algorithms for complex systems and decision processes. Mamdani-type inference anticipates the output membership functions to be fuzzy sets. After performing the aggregation process, there is a fuzzy set for each output variable that needs defuzzification. It can be build by using either command line functions or with the graphical user interface (GUI) present in the Matlab. In this study, we are using the Mamdani method for the undeniable reasons as it is spontaneous, commonly used, widely accepted and it is suited to system requiring human intervention. In the present study, system is developed by using the GUI tools, which basically consists of five editors to build, edit and view the system, as shown in figure 1, namely

- Fuzzy Inference System (FIS) Editor - it is used for handling the high-level issues for the system like number of input and output variables and their names.

- Membership Function Editor- it is used for defining the shapes of all the membership functions associated with each variable.

- Rule Editor- it is used to edit the list of rules that defines the behavior of the system.

- Rule Viewer- it is used to view the fuzzy inference diagram. It is used to see which rules are active, or how individual membership function shapes influence the results.

- Surface Viewer - it is used to view the dependency of one of the outputs on any one or two of the inputs. It generates and plots an output surface map for the system [7].

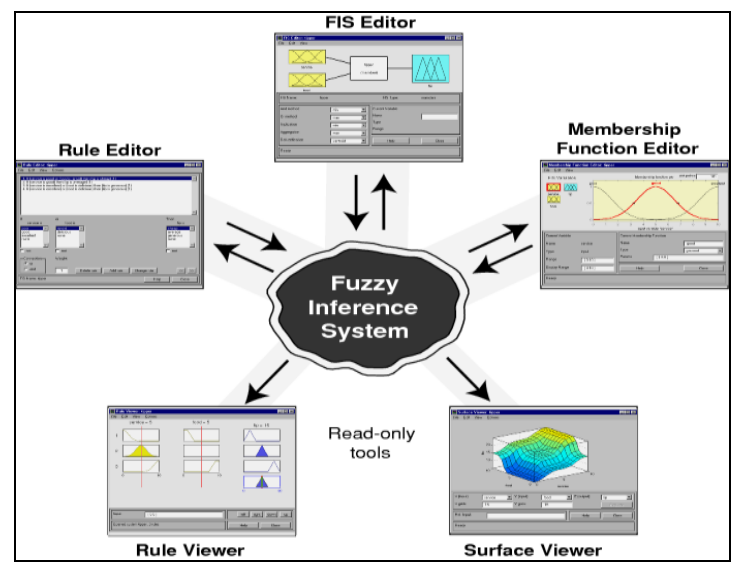

Fig - 1: GUI editors in Mamdani fuzzy method [7]

\section{TSUNAMI GENERATION}

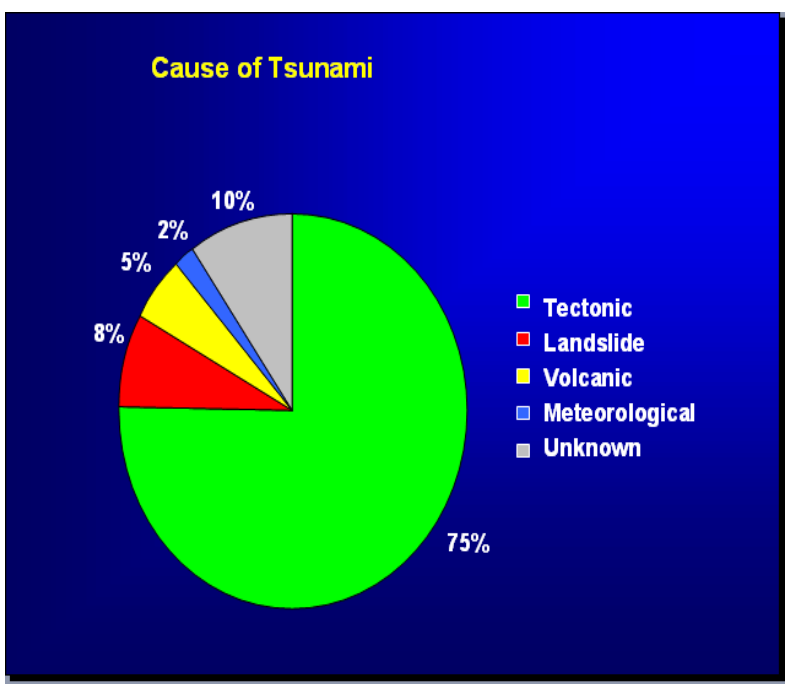

Fig-2: Causes of Tsunami [8]

As shown in figure 2, most of the oceanic tsunamis (up to $75 \%$ of all historical cases) are generated by shallow-focus earthquakes competent of transferring enough energy to the overlying water column. The rest is divided between the landslide $(7 \%)$, volcanic $(5 \%)$ and meteorological $(2 \%)$ tsunamis. Up to $10 \%$ of all the reported historical run-ups still have unidentified sources. Some recent studies show that in fact the fraction of tsunamigenic event where slide-generation mechanism was indulged can be much higher (up to $30 \%$ of all cases) [8]. 


\section{TSUNAMI WARNING SYSTEM}

As discussed above, major causes of tsunami are earthquakes, volcanic eruptions and landslides. So, in prediction or early warning system, these can be used as the parameters. So, here in this study along with these 3 parameters one more parameter, i.e. height of water waves in the deep ocean is taken.

\subsection{Parameters Used}

Basically, as according to the geologists the different causes of tsunami can't be put into a specific range for whole world. The tsunami event triggers according to the place and the according environmental conditions. But based on the historical data of tsunami, the data ranges of the different parameters can be evaluated. In the present study, the ranges are evaluated from the actual existing historical database and the information of tsunami provided by the organizations like NOAA pacific tsunami warning centre, Japan meteorological agency, UNESCO international tsunami information centre, Wikipedia, Indian tsunami agency. All these parameters will be treated as inputs in the fuzzy logic system that will be designed by the help of fuzzy logic toolbox of Matlab. These parameters can be defined as follows-

- Earthquake- A series of vibrations or movements in the earth's crust. Earthquakes that occur besides the coastlines or anywhere underneath the oceans can cause tsunami. The size of the tsunami is usually depends on the size of the earthquake, with larger earthquakes generates larger tsunami. It is measured in Richter scale.

- Landslides- Landslides moving into oceans, bays, or lakes can also cause tsunami. Most such landslides are generated by earthquakes or volcanic eruptions.

- Volcanic eruption- Volcanoes that occur along coastal zones, like in Japan and island arcs throughout the world, can cause several impacts that can become a reason of a tsunami. Explosive eruptions can speedily emplace pyroclastic flows into the water, landslides and debris avalanches generated by eruptions can rapidly move into water, and collapse of volcanoes to form calderas can suddenly displace the water. Measured in VEI (Volcanic Explosivity Index) which varies from 0 to 8 .

- Height of waves in deep ocean- height of tsunami waves in Deep Ocean is very less, not more than 4 meters due to decreases level of potential energy. The height of waves keeps on increasing as waves reach at the shore [9].

\section{METHODOLOGY}

Fuzzy system for tsunami warning system can be designed by applying following procedure in the Matlab Fuzzy Logic Toolbox:
- Inspect the problem to be solved and select the input and output variables. In this study, input variables used are magnitude of earthquake, volcanic eruption, landslide and height of waves and output variable used is alert_type.

- Deciding the fuzzy inference rules. This generally depends on human experience and trial-and-error. The interference rule is selected based on the degree of match and the results of the standards by the organizations like NOAA pacific tsunami warning centre, Japan meteorological agency, UNESCO international tsunami information centre, Wikipedia, Indian tsunami agency. The values are rounded off to fit linguistic terms.

- Fuzzy membership functions for all the inputs and the output. Fuzziness in a fuzzy set is illustrated by its membership functions. It distinguishes the element in the set, if it is discrete or continuous. This includes determining the position, shape as well as overlap between the adjacent membership function, as these are major factors in determining the performance of the fuzzy logic. In defining membership function, different geometric shapes such as triangular, trapezoidal, or curved etc are used. The selection depends upon the one's knowledge and understanding of the process. In this study, we are considering trapezoidal membership function as it is most commonly used shape and moreover, it is best describing the current problem.

- Performing fuzzy inference based on the inference method. Smoothness of the final control surface is determined by the inference and defuzzification methods.

- Choose a defuzzification method. Defuzzification means the fuzzy to crisp conversions. As the output through the fuzzy system is also fuzzy. So, it needs to be converted into a crisp value to use it practically. Different methods are used for defuzzifying the fuzzy output functions, like, Centroid method, weighted average method, Centre of sums, Centre of largest area and so on. Most commonly used method is centroid method, which is being used in this study.

Precisely, a fuzzy decision is the outcome of weighing the facts and its importance in the same way that humans make decisions. Fuzzy logic imitates human like thinking where the human can figure out an imprecise inference from a collection of imprecise premises [7].

\subsection{Input/ Output Membership Functions}

There are 4 inputs in this system. Each input is described by using the different membership functions such as low, moderate and extreme as according to their ranges. The output alert_type is described by the membership functions rare_alert, advisory_alert and warning_alert. The output of 
system will be rare_alert if no tsunami is likely to occur, advisory_alert if there may be chances of tsunami in near future and warning_alert if tsunami is definite and can be destructive. These functions represent a degree of a binary value, 1 being the highest and 0 being the lowest. All the inputs and output are described by using trapezoidal membership function. It will create uniformity in the system. All the membership functions are shown in the following figures

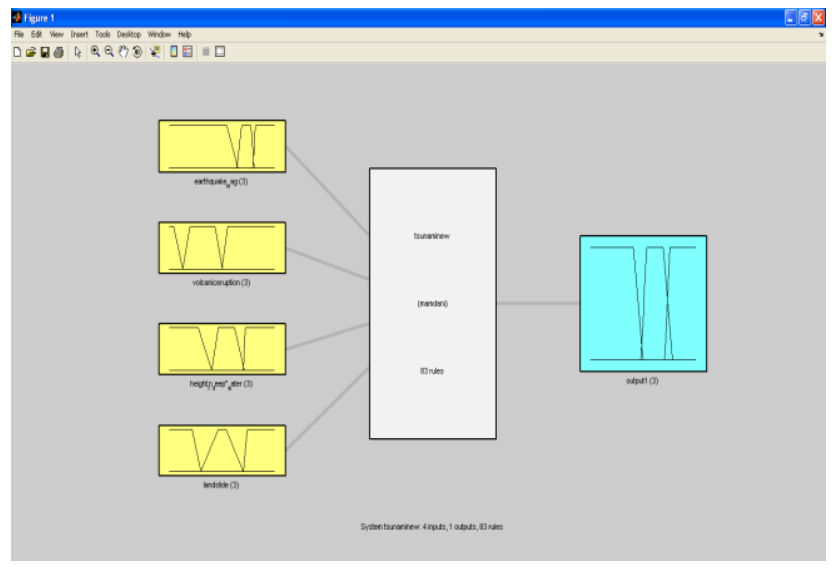

Fig-3: Fuzzy Model for tsunami warning system

Based on the information gathered, the ranges to be used as the membership values in the fuzzy system can collectively be described in the table 1 below which are used in defining the membership functions.

Table 1: Ranges of Different Input

\begin{tabular}{|c|c|}
\hline Parameter & Value \\
\hline Earthquake & $\begin{array}{ll}- & 0 \text { to } 6.3->\text { low } \\
- & 6.4 \text { to } 8 \text {-> moderate } \\
- & 8.1 \text { to } 9.9->\text { extreme } \\
\end{array}$ \\
\hline Volcanic eruption & $\begin{array}{lll}- & 0 \text { to } 0.8 \quad-> \\
& \text { non_explosive } \\
\text { - } & 0.9 \text { to } 4 \text {-> explosive } \\
- & 4.1 \text { to } 7.9 \text {-> } \\
& \text { extreme_explosive }\end{array}$ \\
\hline Landslide & $\begin{array}{ll} & 0 \text { to } 2.9->\text { low } \\
- & 3 \text { to } 7 \text {-> moderate } \\
\text { - } & 7.1 \text { to } 9.9 \text {-> extreme }\end{array}$ \\
\hline $\begin{array}{l}\text { Height of waves in deep } \\
\text { ocean }\end{array}$ & $\begin{array}{ll} & 0 \text { to } 3.9->\text { dangerous } \\
- & 4 \text { to } 7.1 \\
\text { may_be_tsunami } \\
\text { - } & 7.2 \text { to } 10->\text { normal }\end{array}$ \\
\hline
\end{tabular}

Using these ranges, the tsunami alert type can be predicted. Also, the output membership values used in the fuzzy system is 12 -point scale of tsunami intensity was proposed in 2001 by
Gerassimos Papadopoulos and Fumihiko Imamura. The tsunami scale is arranged according to a tsunami's effects on humans (a), effects on objects including boats (b), and damage to buildings (c) [10]. Based on these 12 points, the output membership values are grouped as follows-

- Rare tsunami alert- 0-7

- Advisory tsunami alert-7-10

- Major Tsunami warning-10-12

If rare is the alert output from the system then, there is nothing to worry about. Tsunami will not occur.

If advisory is the alert, then tsunami may happen. General people are advised to be in contact with the local organizations and keep on hearing news.

If warning is the output, definite tsunami will be there. General public is warned about the danger and advised to move from the area. The situation can be devastating and destructive.

The membership functions of inputs and output are as shown in figures

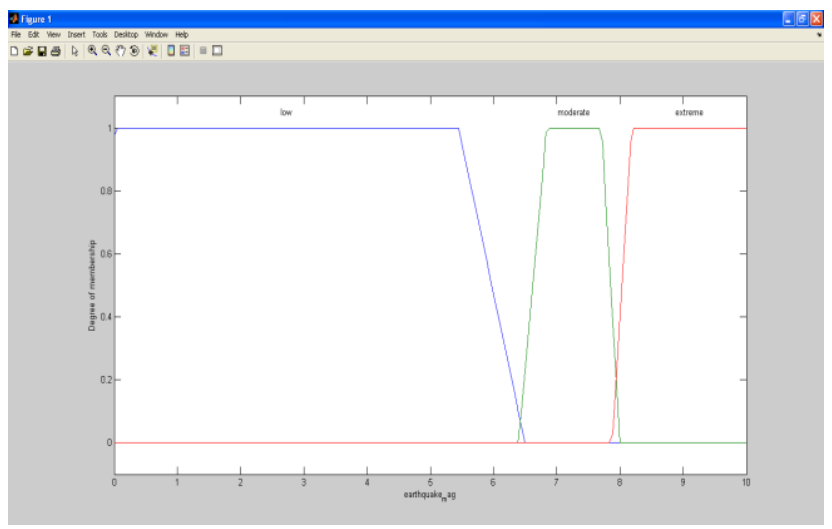

Fig-4: Membership Function for input earthquake.

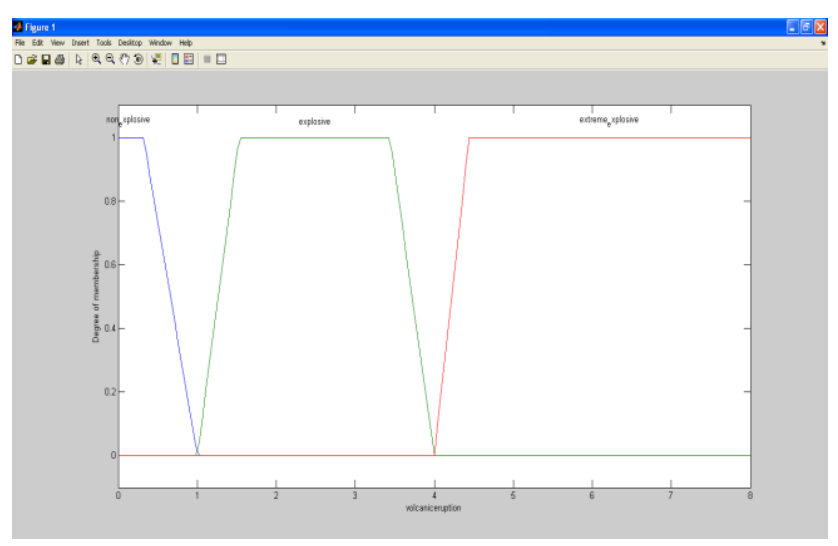

Fig- 5: Membership Function for input volcanic_eruption 


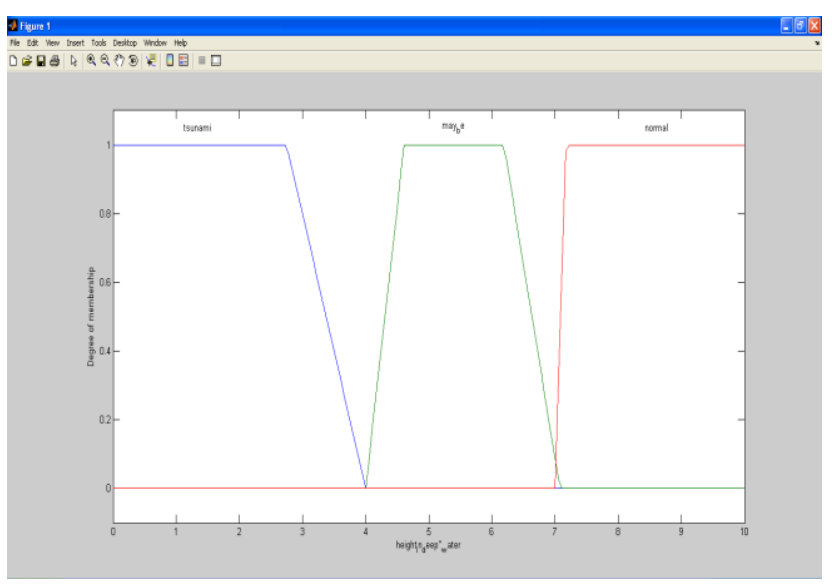

Fig-6: Membership Function for input height_in_deep_ocean

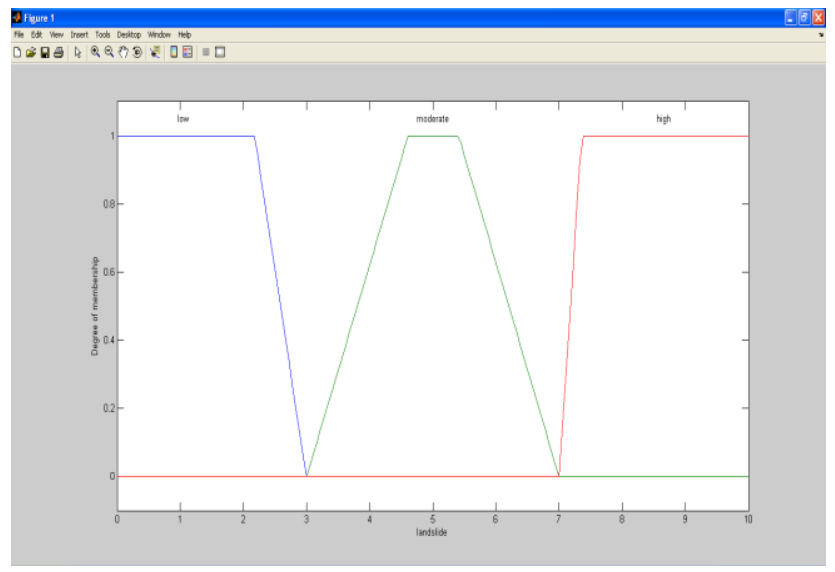

Fig-7: Membership Function for input landslide

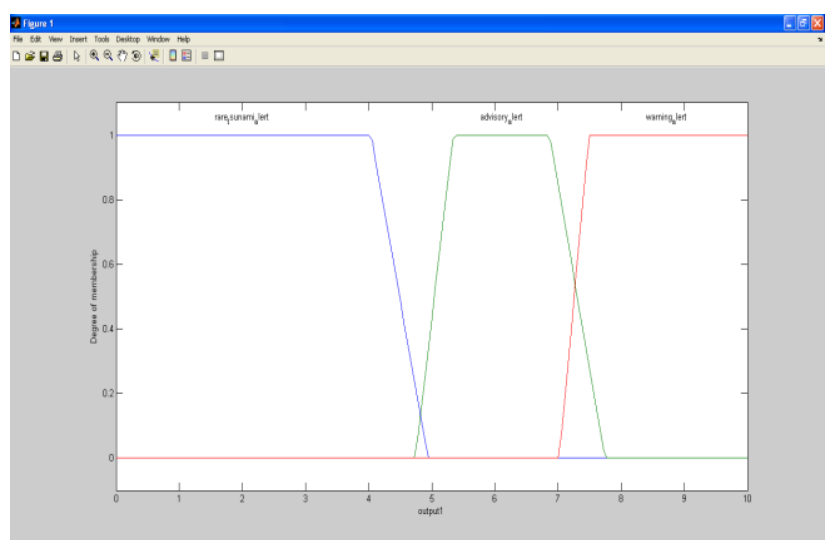

Fig-8: Membership Function for output alert_type

\subsection{Fuzzy Rules}

Fuzzy rules play the most important part in the fuzzy system. These rules can be decided on the basis of one's knowledge or understanding. As here, we are using the standardized data for all the inputs; fuzzy rules are dependent on them. The fuzzy rules basically are in the form of IF $x$ then $y$. In the Matlab Fuzzy Logic Toolbox, there is a rule editor to enter the rules and edit them if required. 83 rules are used for the current water quality estimator. The rule editor for our quality estimator is shown in the figure 9. There are three formats in which rules can be entered in the rule editor, that are either verbose, which is being used in the current study, or symbolic or indexed [7]. A rule is defined in the following way:

1. If (earthquake_mag is extreme) and (volcaniceruption is non_explosive) and (height_in_deep"_water is tsunami) and (landslide is low) then (output1 is warning_alert)

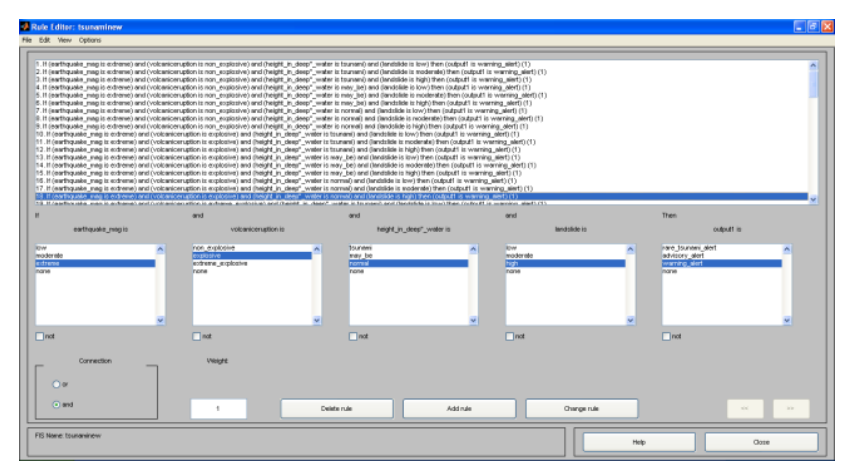

Fig-9: Rule Editor for Tsunami Warning System

\subsection{Simulations}

We have conducted a number of experiments by entering the different values of the inputs and every time the system is giving correct output as it was assumed according to our acquired knowledge and information according to historical databases. Rule viewer is used to enter your inputs and see how each and every rule is behaving on your given input. Finally, it gives one defuzzified crisp output based on the method you had used. We are using centroid method in the current study. For example, when we take input as [ [ $\left.\begin{array}{llll}4 & 0.5 & 8 & 1\end{array}\right]$. According to us, the output should be rare_alert as all the inputs are in the range when there is no possibility of tsunami. When simulated from the system we have designed, the results are coming to be as, shown in figure 10 .

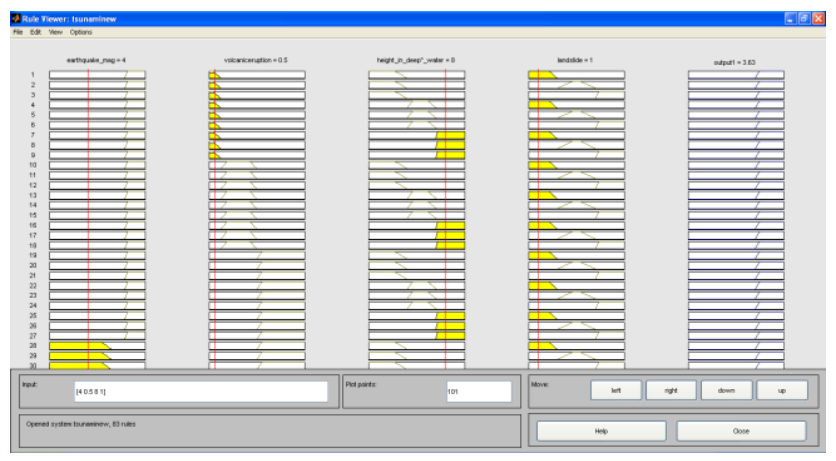

Fig-10: Rule Viewer for input described above 
Defuzzified value comes out to be 3.63 , which is under the rare_alert range. Surface viewer is also used to show the output behavior with respect to the inputs. Basically, it works well for 2 input and 1 output system. As number of inputs increased, any two inputs can be selected as $\mathrm{x}$ and $\mathrm{y}$ axis and the output can be mapped accordingly. Here, in the present study as there are 4 inputs so according to the different inputs on $\mathrm{x}$ and $\mathrm{y}$ axis, output alert_type can be mapped as shown in the following figures below

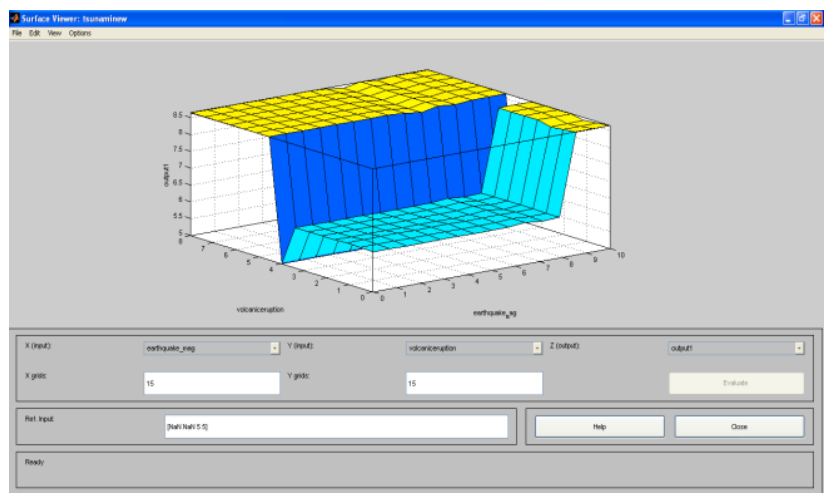

Fig-11: Surface viewer with earthquake and volcanic_eruption as inputs

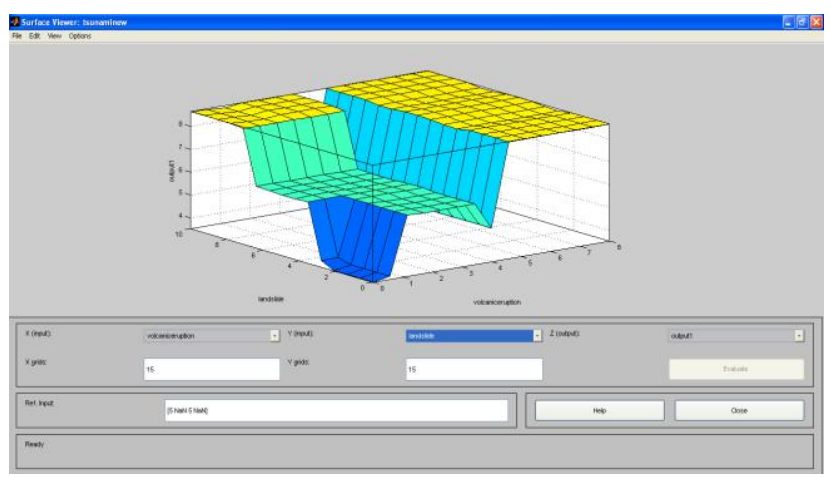

Fig-12: Surface viewer with volcanic_eruption and landslide as inputs

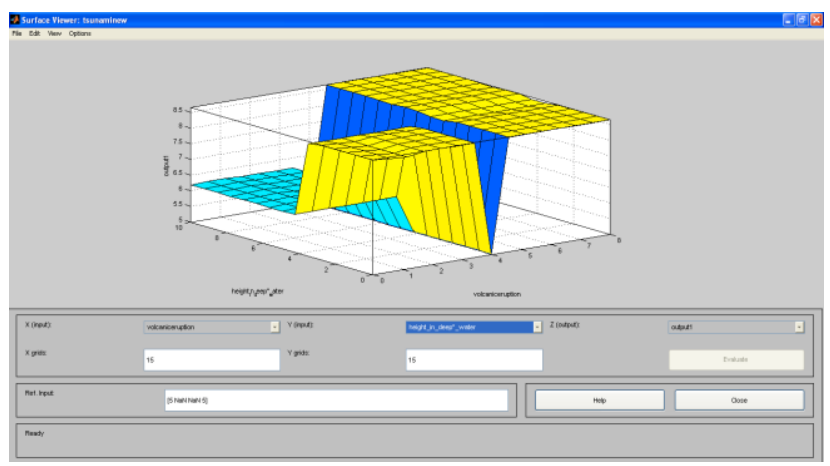

Fig-13: Surface viewer with volcanic_eruption and height_in_deep_ocean as inputs

\section{RESULTS AND ANALYSIS}

On conducting a number of experiments with different data sets, each time we are getting the correct output. As when we input the data as described above the result should be that alert will be rare_alert. When applied, we are crisp output value as 3.63 , which is under the range of rare. So, the result according to the fuzzy model is also that alert will be rare_alert, no tsunami is likely to occur. In the same way, for different inputs we are getting correct results as expected.

We have compared our work with the work in the IEEE research paper "Cherian, Carathedathu Mathew, Nivethitha Jayaraj, and S. Ganesh Vaidyanathan, "Artificially Intelligent Tsunami Early Warning System." In Computer Modeling and Simulation (UKSim), 2010 12th International Conference on, pp. 39-44. IEEE, 2010" [11]. In this paper, they have taken only 2 parameters, but we have taken 4 number of inputs as along with the earthquake, landslides and volcanic eruptions are also causes tsunami in the several regions and many major and devastating tsunamis due to volcanic eruptions and landslides have recorded in the past. They had also implemented the problem in the Matlab Fuzzy Logic Toolbox as we have. We have taken standardized data according to the well known authorities NOAA pacific tsunami warning centre, Japan meteorological agency, UNESCO international tsunami information centre, Wikipedia, Indian tsunami agency and defined our membership functions for each input according to the standard ranges. As they had taken 2 inputs, they are using 12 rules to describe the system whereas we are using 83 rules to describe the system,. We have uniformity in our system as we have described all the inputs by the trapezoidal membership functions. They had divided the different parameters into various no. of ranges, like for output they are using 5 sets, where as we are taking 3 sets namely rare, advisory and warning, which is more realistic situation and easy to understand. Moreover, when compared with this existing system, our system is found to be more capable and is giving better results.

\section{CONCLUSIONS}

Fuzzy logic provides an alternative to represent linguistic and subjective aspects of the real world in computing. The intention behind the selection of fuzzy logic model in this study is that system uses fuzzy logic model conveys valuable and real results depending on the uncertain, vague, indecisive and imprecise verbal knowledge just like logic of a human being. Moreover, it takes long time to use the other methods for such problem and by using fuzzy we can reach a general solution by doing only limited number of experiments. Mamdani has been designed in this study. The prediction scheme presented here can be considered as a step towards this natural hazard tsunami which results in destruction on a high level. This can successfully be applied by taking other parameters into consideration and moreover, in this study general data has been evaluated from the historical database, 
this system can work more efficiently if data for a particular area is used.

\section{REFERENCES}

[1]. http://en.wikipedia.org/wiki/Tsunami

[2]. http://www.pbs.org/wgbh/nova/tsunami/

[3]. L.A. Zadeh, "Fuzzy Sets," in Information and Control, vol. 8. New York: Academic Press, 1965, pp. 338-353.

[4]. R. E. Bellman and L. A. Zadeh, "Decision-making a fuzzy environment," Management Science, vol. 17, pp. 141164,1970 .

[5]. K. Tomsovic and M.Y.Chow," Tutorial on Fuzzy Logic Applications in Power Systems" IEEE-PES winter meeting, Singapore, 2000

[6]. Poongodi, M., Manjula, L., Pradeepkumar, S. and Umadevi, M.(Dec 2011), Cancer prediction technique using fuzzy logic, International journal of Current Research, Vol. 3, Issue 11, pp. 333-336.

[7]. http://www.mathworks.in/help/fuzzy/building systemswith-fuzzy-logic-toolbox-software.html\#FP6300.

[8]. http://tsun.sscc.ru/tsun_hp.htm

[9]. http://academic.evergreen.edu/g/grossmaz/springle/

[10]. Papadopoulos, Gerassimos A., and Fumihiko Imamura. "A proposal for a new tsunami intensity scale." ITS 2001 Proceedings. No. 5-1. 2001.

[11]. Cherian, Carathedathu Mathew, Nivethitha Jayaraj, and S. Ganesh Vaidyanathan. "Artificially Intelligent Tsunami Early Warning System." In Computer Modeling and Simulation (UKSim), 2010 12th Interntional Conference on, pp. 39-44.IEEE, 2010"

\section{BIOGRAPHIES}

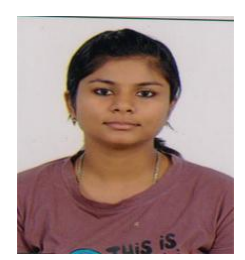

Twinkle Tayal, student of M.tech, $2^{\text {nd }}$ year, CSE, Mody University of Science and Technology. Till now published 3 papers in international journals.

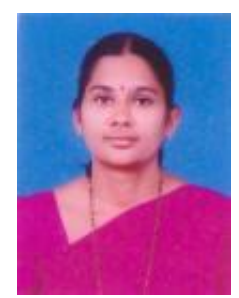

Dr. Prema KV, Head of Department, CSE, FET, Mody University of Science and Technology. Till now has published 17 journal papers and 37 conference papers. Earlier guided $2 \mathrm{PhD}$ and an AICTE(20062009) project and currently guiding $6 \mathrm{PhD}$ Projects. 